\title{
Refúgio ecológico e sistema de produção extensivo de bovinos de corte: exemplo da fazenda Caiman no Pantanal do Mato Grosso do Sul
}

\author{
Kennyson Alves de Souza ${ }^{1}$, Maribel Velandia Valero ${ }^{2}$, Ana Guerrero ${ }^{2}$, Carlos Sañudo ${ }^{3}$, \\ Ivanor Nunes do Prado ${ }^{4}$
}

\author{
${ }^{I}$ Aluno de doutorado do Programa de Pós Graduação em Zootecnia da Universidade Estadual de Maringá. \\ ${ }^{2}$ Alunos de pós doutorado do Programa de Pós Graduação em Zootecnia da Universidade Estadual de Maringá. \\ ${ }^{3}$ Professor catedrático da Universidad de Zaragoza - Espanha. \\ ${ }^{4}$ Professor titular do Departamento de Zootecnia da Universidade Estadual de Maringá. Pesquisador 1A do \\ CNPq. Autor para correspondência.E-mail: inprado@uem.br.
}

\begin{abstract}
RESUMO. A fazenda Caiman está localizada no pantanal do Mato Grosso do Sul. Esta propriedade tem como atividades o eco-turismo e a pecuária de corte. No eco-turismo destacam-se dois importantes projetos: arara azul e Onçafari. No projeto arara azul o principal objetivo é a proteção da arara azul, preservação da espécie e conscientização da população sobre a importância deste animal para o eco-sistema. No projeto Onçafari, o principal objetivo é a preservação da espécie e promover a visita e interação do ser humano a estes animais. Ainda, encontramos casos curiosos como o carinho e respeito dedicado aos bois sinuelos. Estes animais são usados para auxiliar no resgate de bovinos desgarrados ou arribados do rebanho. O mais importante, é que após a aposentadoria destes animais (12 a 15 anos) eles são mantidos no rebanho como símbolo de respeito ao trabalho realizado ao longo da vida. A fonte essencial de recursos para manter a fazenda em atividade é a bovinocultura de corte. No entanto, os índices de produtividades são baixos em função do sistema de produção inerente as condições do pantanal. Em conclusão, este é o único sistema de produção no pantanal em consonância com a natureza.
\end{abstract}

Palavras chave: Ecologia, fazenda Caiman, Mato Grosso, O)nçafari

\section{Ecological refuge and cattle extensive production system: an example of Caiman farm in Pantanal Mato Grosso do Sul}

\begin{abstract}
The Caiman farm is located in the Pantanal of Mato Grosso do Sul. This property has activities like eco-tourism and beef cattle. In eco-tourism highlights are two important project: Blue macav and andonçafari. Blue macaw project the main objective is the protection of blue macaw, species preservation and public awareness of the importance of this animal for the eco-system. In onçafari project, the main objective is the preservation of the species and promotes the visit and interaction of men to these animals. Still, we find curious cases like affection and respect dedicated to sinuelos oxen. These animals are used to assist in the rescue of stray cattle or runaways the herd. The most important is that after the retirement of these animals (12-15 years) they are kept in the herd as a symbol of respect for the work done throughout life. The essential resource for maintaining farm in activity is the beef cattle. However, the productivities rates are low due to the inherent production system of wetland conditions. In conclusion, this is the only production system in Pantanal in harmony with nature.
\end{abstract}

Keywords: Ecology, Cayman farm, Mato Grosso, onçafari

\section{Introdução}

A região do pantanal do Mato Grosso do Sul sempre foi caracterizada pela sua beleza intrínseca e pela exploração extensiva de bovinos de corte (ANUALPEC, 2014). No entanto, no final do século passado e início deste século, algumas modificações estão ocorrendo, sobretudo, na exploração mais racional do ecosistema da região. Desta forma, a integração do sistema de produção extensivo de gado de corte e implantação de fazendas como refúgios 
ecológicos está ocorrendo de forma significativa. Vários são os exemplos desta integração. No presente caso, faremos o relato de uma integração entre o sistema extensivo de bovino de corte e a implantação de um sistema para manutenção e respeito à vida animal e vegetal do pantanal do Mato Grosso do Sul. Em recente visita na Fazenda Caiman, descobriu-se que é possível manter de forma adequada e eficiente um sistema de criação extensiva de gado de corte e um sistema de sustentabilidade da realidade da região.

\section{Localização geográfica da fazenda Caiman}

A fazenda Caiman está localizada na cidade de Miranda, no Pantanal do Mato Grosso do Sul (Foto 1).

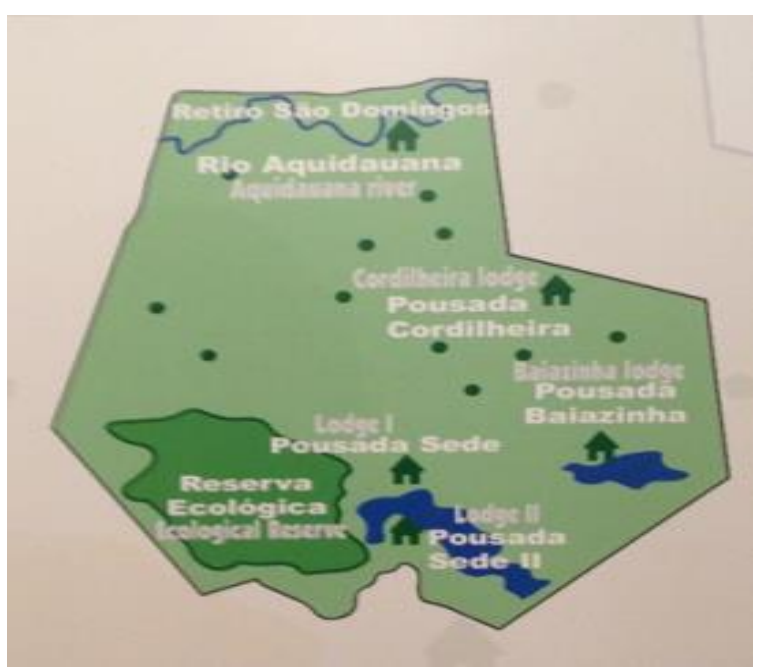

Foto 1. Mapa da fazenda

O clima da região é tropical úmido com verão chuvoso e inverno seco. A temperatura média anual é de $25^{\circ} \mathrm{C}$ e umidade relativa de $82 \%$,mas pode ocorrer temperatura abaixo de $10^{\circ} \mathrm{C}$.

A quantidade de chuva varia entre $1.000 \mathrm{e}$ $1.400 \mathrm{~mm}$ ao ano. O período de cheia está entre fevereiro e maio. O período de vazante está entre os meses de abril e julho. Entre os meses de julho a outubroocorre o período seco. As chuvas estão concentradas entre os meses de novembro ajaneirode cada ano.

\section{Caracterização e atividades da fazenda Caiman}

O refúgio ecológico Caiman é constituído em uma fazenda com duas pousadas com capacidade para 22 pessoas, e ainda, conta com mais duas sedes que pode acolher grandes grupos de pessoas. A fazenda iniciou efetivamente suas atividades em 1984 baseadas em três principais pilares: pecuária, ecoturismo e pesquisa de conservação. Na realidade, a pecuária é o maior pilar de sustentação das atividades. $\mathrm{O}$ ecoturismo poderá ser o grande futuro da emprese e a pesquisa de conservação é o desafio da região.

As atividades de ecoturismo da fazenda Caiman são caracterizas por caminhadas na mata, passeios em canoas, safáris fotográficos e visualização de animais que revela a beleza do pantanal brasileiro.

\section{Exploração do sistema agro-ecológico}

$\mathrm{Na}$ fazenda Caiman são desenvolvidos vários projetos de sustentação a natureza, entre eles, proteção da arara azul e onçafari.

No início do projeto arara-azul contava-se com uma população de 100 araras na fazenda e cerca de oito ninhos naturais. Atualmente, são 400 araras azuis e 120 ninhos, sendo 60 naturais e 60 instalados pelo homem, dos quais $70 \%$ são utilizados pelas araras azuis (Foto 2).

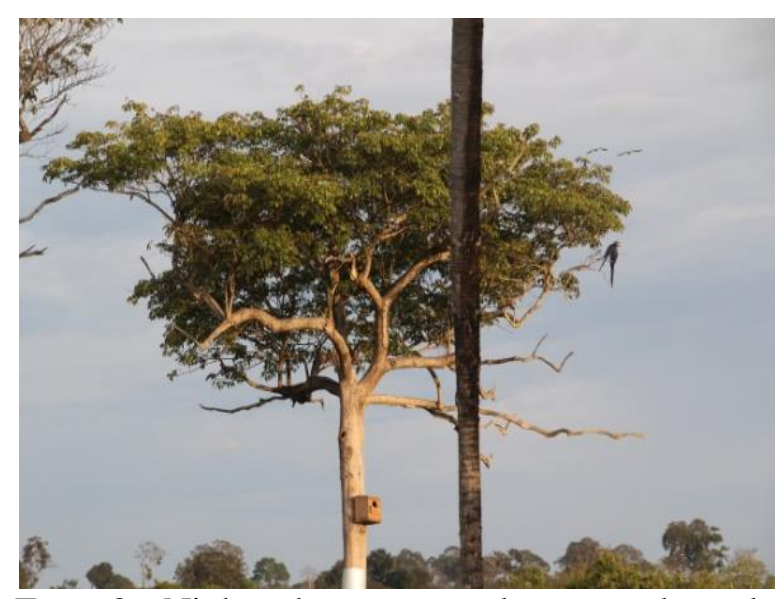

Foto 2. Ninho de arara azul preparado pelo homem

Embora, o objetivo do projeto é apoiar principalmente as araras azuis, ameaçada de extinção, o trabalho envolve também a proteção de outros pássaros permitindo a conservação da biodiversidade pantaneira a qual conta com mais de 5000espécies(Foto 3).

O projeto da arara azul conta com o apoio financeiro da Fundação Toyota do Brasil, assim como, com a participação do proprietário da fazenda Caiman. Dentro do projeto trabalham seis técnicos pesquisadores da área.

Além da proteção dos animais o projeto tem como objetivo o estudo do comportamento dos animais e a conscientização da população sobre o perigo de extinção da arara azul. No que concerne á conscientização o projeto tenta 
mostrar à população da região a proibição da exportação da ave para outros países do mundo, como por exemplo, Estados Unidos, Canadá e União Europeia, embora exista grande vantagem econômica. Esta proibição e conscientização da população estão salvando as araras azuis do pantanal sul do Mato Grosso. A principal alimentação da arara azul é o fruto produzido por duas arvores da região: acuri e bocaiúva. Desta forma, o projeto mostra à população a importância de manter esta flora natural.

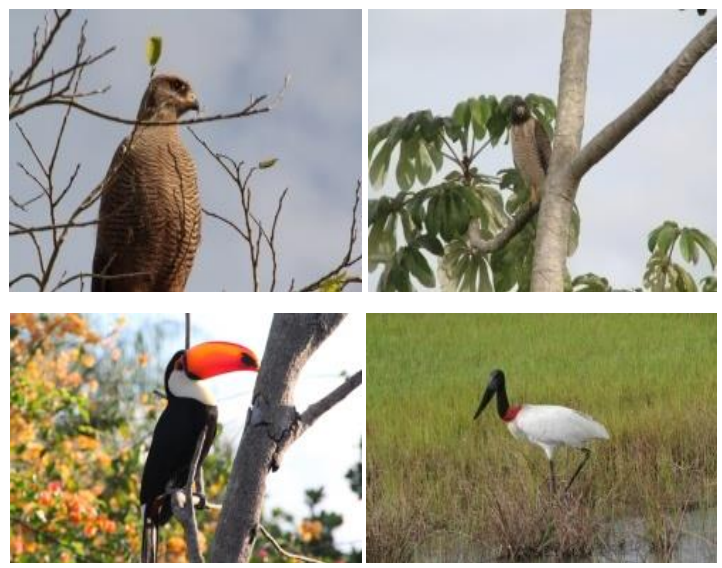

Foto 3. Outros pássaros da região

Por outro lado, o principal objetivo do Onçafari é desenvolver uma técnica para conservação da onça pintada do Brasil, por meio do eco-turismosustentável de observaçãona região do Mato Grosso do Sul. A onça pintada pode ser observada pelos turistas durante a visita na Fazenda Caimantanto nos passeios diurnos como nas focagens noturnas (Foto 4).

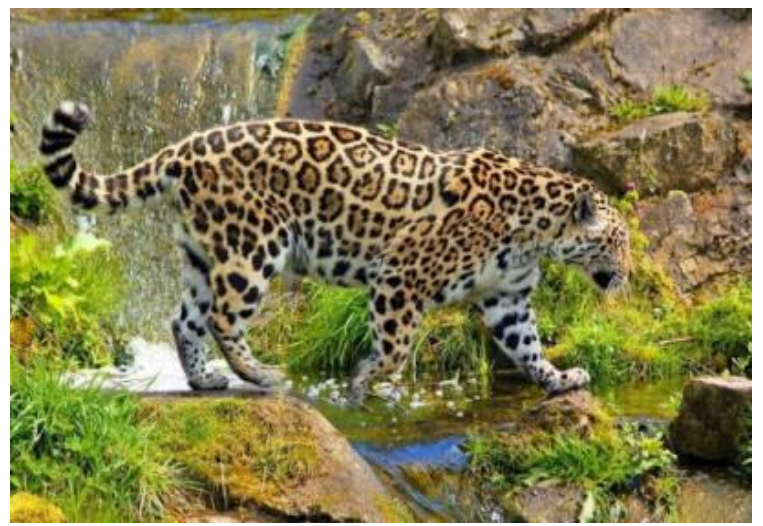

Foto 4. Onça pintada

A inspiração das técnicas bem sucedidas em outras regiões do planeta com diversas espécies como seria na África do Sul com os leopardos, no Canadá com os ursos, em Uganda com os gorilas, entre outros, inspirou o atualmodeloquepermitea observação de onças pintadas em seu habitat natural. Este processo não envolve qualquer método de domesticação da onça pintada ou outra atitude que desequilibre seu habitat natural. Este projeto visa acostumar às onças pintadas à presença do homem e veículos como se estes fizessem parte do cenário pantaneiro. O programa da onçafari é considerado o principal atrativo dos turistas que visitam a fazendaCaiman. Todavia, como comentado pelos guias, a visualização da onça pintada é de extrema oportunidade. Poucos são os visitantes que têm a oportunidade de visualizar este animal durante o período de visita à fazenda Caiman porem as múltiplaspegadasdemonstra ao visitante à proximidade das onças.

Ao contrário da onça pintada, como o próprio nome caracteriza a fazenda, a presença de jacarés ou caimans é uma constante durante todo o período de visita (Foto 5).

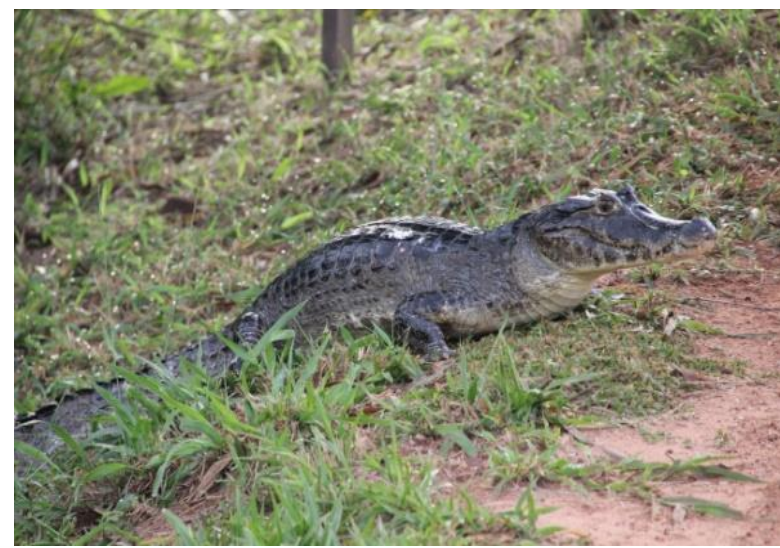

\section{Foto 5. Jacaré}

Este animal esteve ameaçado no pantanal há alguns anos atrás. Todavia, com a proibição da exportação e desinteresse da população dos países mais desenvolvidos em adquirir produtos confeccionados com a pele de jacaré, houve um aumento significativo deste animal no pantanal. Desta forma, a população do jacaré ou caiman está muito bem estabelecida. Da mesma forma, a presença de capivaras e porco selvagem é uma constante na fazenda Caiman (Foto 6).

Ao lado das belezas mais utilizadas pela empresa para promover o eco-turismo na região observamos outras características tão atrativas como o principal marketing da fazenda Caiman; a presença dos bois sinuelos (Foto 7).

Estes animais são utilizados para resgatar outros bovinos que se encontram desgarrados do rebanho e estão dentro das matas. Por um sistema característico na região, os bois desgarrados ou arribados são atados a uma argola em dois pontos (boi sinuelo um ponto e boi desgarrado outro 
ponto) e trazidos até o local de manejo dos animais. $\mathrm{O}$ boi sinuelo é considerado uma dádiva singular para o criador de bois por facilitar seu serviço. Desta forma, ao final do período de trabalho, que duram de 12 a 15 anos, estes animais são mantidos e bem cuidados na propriedade em reconhecimento aos trabalhos de prestação de serviço durante sua vida ativa. Desta forma, estes animais envelhecem e morrem na propriedade sem a mínima possibilidade de comercialização, como por exemplo, para abate e consumo humano. Segundo os peões da propriedade esta é uma cultura do povo pantaneiro, respeitando o animal que o auxiliou no trabalho árduo de recuperar bois "perdidos".
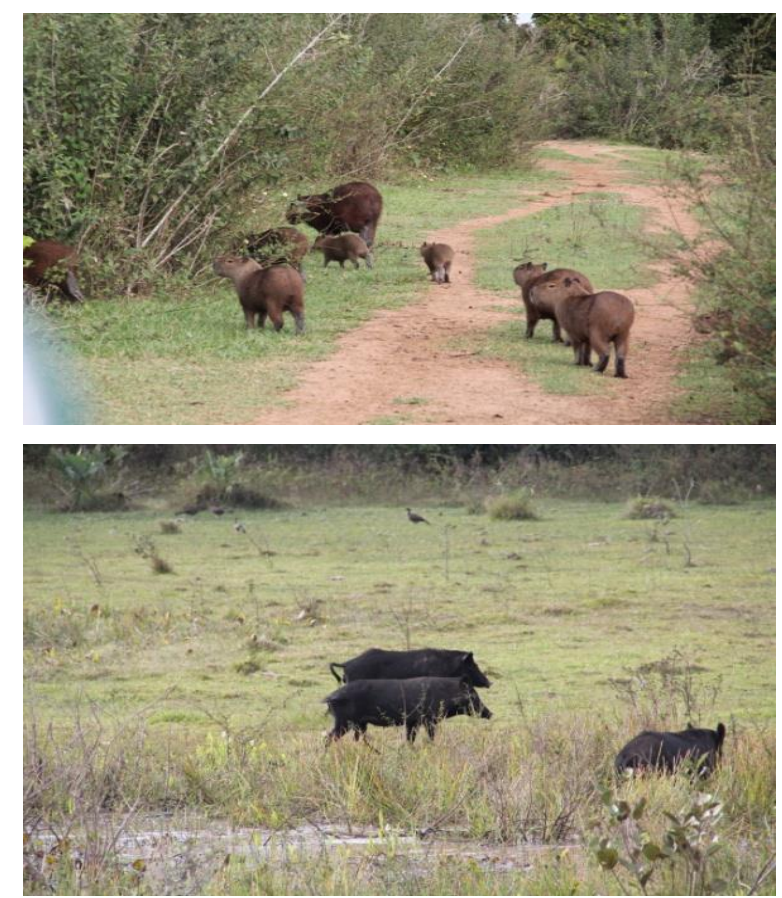

Foto 6. Capivara e porco do mato

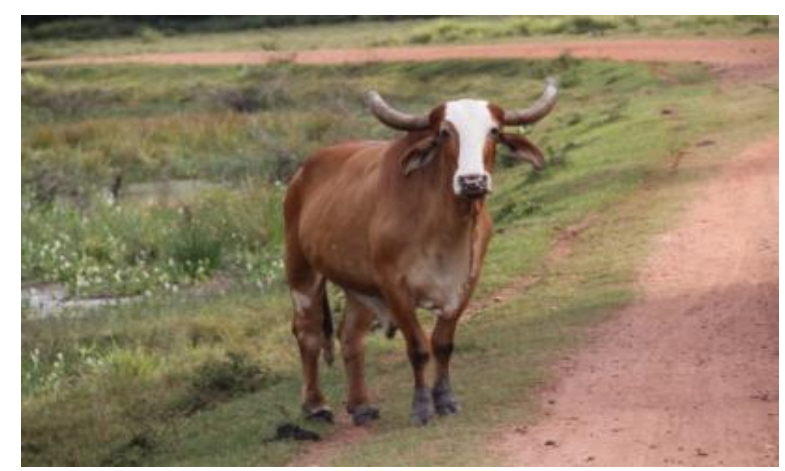

Foto 7. Boi sinuelo.

\section{Exploração extensiva de bovinos de corte}

A principal atividade da fazenda Caiman é a criação extensiva de bovino de corte. A fazenda conta com aproximadamente 30.000 hectares de pastagens. Neste espaço físico estão alojados aproximadamente 30.000 animais, com predominância, da raça Nelore. Desta forma, a taxa de lotação seria de aproximadamente um animal por hectare, lotação esta denominada baixa(Prado, 2010). Todavia, esta taxa de lotação representa mais ou menos a média da taxa de lotação do Brasil (ANUALPEC, 2014). No entanto, em regiões com uso intensivo de criação de bovinos esta taxa pode ser próxima de quatro unidades animal por hectare(Cano et al., 2004).

A raça Nelore é utilizada por estar muito bem adaptadaàs condições do pantanal do Mato Grosso Sul (Figura 8).

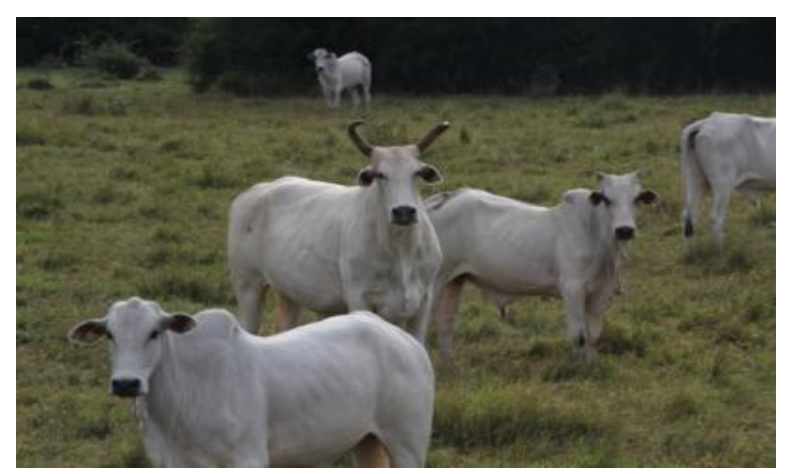

Foto 8. Boi Nelore.

Estes animais, além de estarem bem adaptados às condições de clima, suportam as condições mais agressivas do habitat do pantanal: temperatura, enchentes, precipitação pluviométrica, alimentação e sistema de manejo da região(Batista et al., 2012)

Por outro lado, encontram-se dois tipos característicos de pasto da região: Brachiaria humidicula (Figura 9) e Brachiaria decumbes (Figura 10).

A Brachiaria humidicula é nativa das regiões mais baixas e, portanto, mais alagadas do pantanal. Esta planta suporta terreno mais úmido; todavia, sua produção de massa seca por área é baixa e sua qualidade nutricional é deficiente. A produção de massa seca por hectare é menor do que $2.000 \mathrm{~kg}$ e os teores de proteína bruta e NDT são menores que 6 e 50\%, respectivamente (Abreu et al., 2004).

Assim sendo, o baixo desempenho animal, porem, rentável pelo elevado número de animais abatidos e repostos mensalmente para a terminação. Nas áreas de Brachiáriahumidicula não ocorre correção de solo e nem o uso de adubação. Estas práticas estão inviabilizadas por 
dois motivos principais: poluição da área e recuperação desta mesma área durante o período de enchente.

Por outro lado, as áreas de Brachiaria decumbes estão localizadas nas regiões mais elevadas da fazenda, onde não ocorre alagamento durante o período de cheia. De modo geral, nestas áreas são terminados os animais para o abate, em função da melhor qualidade das pastagens. Ainda, nas áreas de Brachiária decumbes pode ocorrer alguma correção de acidez e adubações. As áreas de Brachiaria decumbens foram semeadas após a correção de solo e certa adubação.
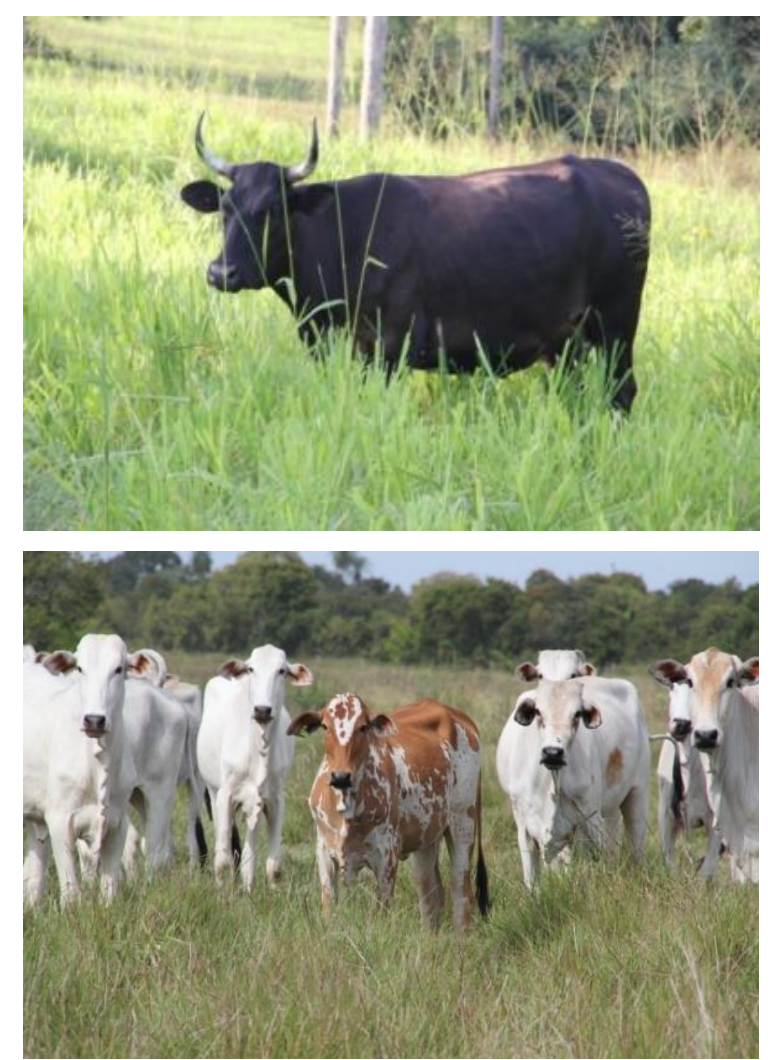

Fotos9 e 10. Brachiaria decumbes e Brachiaria humidicula.

\section{Compatibilidade do sistema eco-sistema ecológico e produção extensiva de bovinos de corte}

Nas condições do pantanal do Mato Grosso do Sul podemos observar que existe uma ligação muito próxima entre o sistema extensivo de produção de bovinos e o eco-turismo. Na realidade, uma atividade não poderia sobreviver sem a outra, sobretudo, o eco-turismo. Até recentemente o eco-turismo era uma atividade quase inexistente na região. Desta forma, para a sobre vida inicial desta atividade, ela necessita ter uma parceria estreita com a atividade de criação de bovinos de corte.

Por outro lado, o sistema de bovino de corte poderá extrair muita curiosidade com o ecoturismo.

\section{Considerações finais}

O sistema de produção extensiva de bovino de corte e eco-turismo poderia apresentar alguma complementaridade.

O sistema de produção extensivo é a real existência do pantanal do Mato Grosso do Sul. Desta forma, não seria viável apresentar modelos muito diferentes do existente por vários motivos; sendo o principal deles o respeito ao eco-sistema. $\mathrm{O}$ respeito ao eco-sistema resulta em uma variável interessante à região: produção de animais sem agredir o meio.

Por outro lado, acreditamos que os investimentos que estão sendo realizados no momento no pantanal do Mato Grosso do Sul poderão ser viáveis em médio espaço de tempo e possibilitar à região uma sobre vida saudável no futuro.

\section{Agradecimentos}

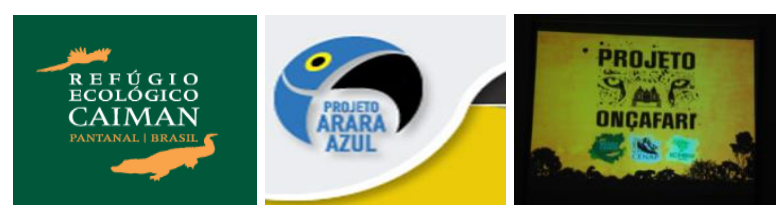

\section{Referências Bibliográficas}

Abreu, J. B. R., Cóser, A. C., Demicis, B. B., Brum, R. P., Sant'ana, N. F., Teixeira, M. C. \& Santos, A. M. (2004). Avaliação da produção de matéria seca, relação folha/colmo e composição químico-bromatológica de Brachiaria humidicola (rendle), submetida à diferentes idades de rebrota e doses de nitrogênio e potássio. Revista Universidade Rural: Série Ciência da Vida, 24(1), 135-141.

ANUALPEC. (2014). Anuário da Pecuária Brasileira (20th ed. Vol. 1). São Paulo, SP, Brasil: Instituto FNP.

Batista, D. S. N., Abreu, U. G. P., Bahiense, P., Filho, F. \& Nascimento Rosa, A. (2012). Índices reprodutivos do rebanho Nelore da fazenda Nhumirim, Pantanal da Nhecolândia. 
Acta Scientiarum. Animal Sciences, 34(1), 7176.

Cano, C. C. P., Cecato, U., Canto, M., Rodrigues, A. B., Jobim, C. C., Rodrigues, A. M., Galbeiro, S. \& Nascimento, W. (2004). Produção de forragem do capim-tanzânia (Panicum maximum Jacq. cv. Tanzânia-1) pastejado em diferentes alturas. Revista Brasileira de Zootecnia, 33(6), 1949-1958.

Prado, I. N. (2010). Produção de bovinos de corte e qualidade da carne (Vol. 1). Maringá, Paraná, Brasil: Eduem.
Recebido em Junho 10, 2015

Aceito em Agosto 27, 2015

License information: This is an open-access article distributed under the terms of the Creative Commons Attribution License, which permits unrestricted use, distribution, and reproduction in any medium, provided the original work is properly cited. 